\title{
Norois
}

Environnement, aménagement, société

229 | 2013

Ruralités, géomorphologie littorale, toponymie, corps et imaginaire

\section{Dépoldériser en Europe Occidentale}

\section{Michel Desse}

\section{(2) OpenEdition \\ Journals}

Édition électronique

URL : http://journals.openedition.org/norois/4870

DOI : $10.4000 /$ norois. 4870

ISBN : 978-2-7535-3409-4

ISSN : $1760-8546$

\section{Éditeur}

Presses universitaires de Rennes

\section{Édition imprimée}

Date de publication : 20 décembre 2013

Pagination : 87-89

ISBN : 978-2-7535-3384-4

ISSN : 0029-182X

\section{Référence électronique}

Michel Desse, «Dépoldériser en Europe Occidentale », Norois [En ligne], 229 | 2013, mis en ligne le 30 mars 2014, consulté le 23 septembre 2020. URL : http://journals.openedition.org/norois/4870 ; DOI : https://doi.org/10.4000/norois.4870

\section{(c) Tous droits réservés}




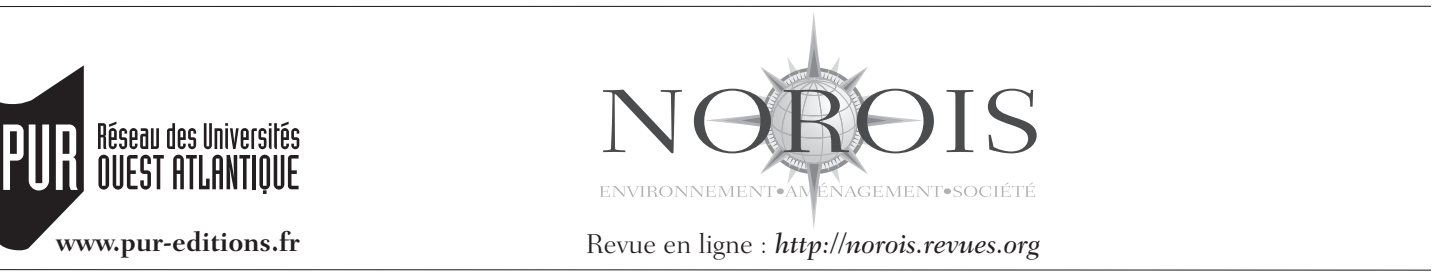

Lydie Goeldner-Gianella, 2013, Dépoldériser en Europe Occidentale, pour une géographie et une gestion intégrée du littoral, Paris, Publications de la Sorbonne, collection «Territoires en mouvements », $350 \mathrm{p}$.

L'ouvrage de Lydie Goeldner-Gianella, Dépoldériser en Europe Occidentale, pour une géographie et une gestion intégrée du littoral a été édité aux publications de la Sorbonne dans la collection «Territoires en mouvement ». L'ouvrage de 336 pages et 6 planches de photographies et cartes en couleur correspond aux travaux de HDR présentés par l'auteure. Il s'agit ici d'une œuvre remarquable par la thématique abordée, la lecture aisée et illustrée de photographies, cartes et graphiques qui permettent au lecteur de s'approprier les 67 cas de dépoldérisation analysés avec finesse.

L'ouvrage s'articule autour de quatre thématiques qui constituent les éléments de la démonstration : Dépoldériser après dix siècles de conquête sur la mer, les fondements paradoxaux mais rationnels de la dépoldérisation, moteurs et entraves à l'essor de la dépoldérisation et enfin pour une participation des populations locales au processus de dépoldérisation.

D'emblée, Lydie Goeldner-Gianella se positionne dans le champ des recherches géographiques contemporaines «dans la progression désormais affirmée d'une géographie littorale plus soucieuse de la globalité..., cette étude se rattache à une géographie sociale de l'environnement soulignant la grande importance des processus sociaux ».

Les littoraux de l'Europe du Nord sont les plus artificialisés et c'est dans ces régions que le nombre de

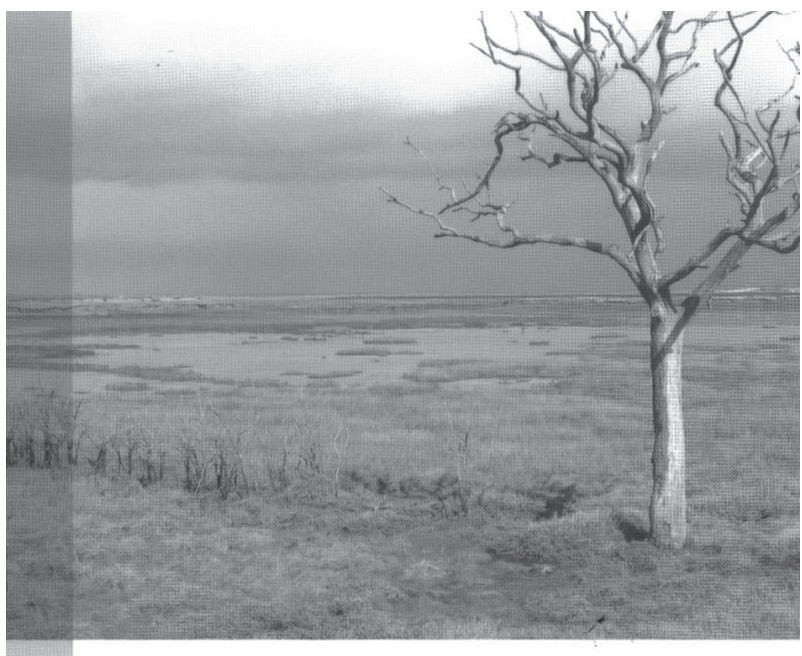

LYDIE GOELDNER-GIANELLA

DÉPOLDÉRISER EN EUROPE OCCIDENTALE

Pour une géographie et une gestion intégrées du littoral polders qui constituent « des terres conquises sur la 
mer par endiguement des marais maritimes et estuariens » sont les plus nombreux. La poldérisation c'est étendue sur $15000 \mathrm{~km}^{2}$ et c'est développée dans des contextes démographiques et économiques particuliers à des fins productives, démographiques et défensives jusqu'aux années 1990. Depuis 35 ans le processus de dépoldérisation s'étend en Europe (1981, pour le marais de l'Aber en France), de manière variable entre les différents pays et recouvre des terminologies propre à chaque langue, à chaque réalité : de la brèche accidentelle à la destruction volontaire d'une vanne ou d'une digue ou à la suite des politiques de réalignement du trait de côte en Grande-Bretagne. À chaque fois, les surfaces dépoldérisées varient de 1 à 853 hectares. Les plus grandes surfaces se retrouvent en Allemagne et aux Pays-Bas. L'un des objectifs de cette recherche est de combler le trop faible nombre d'études portant sur l'intérêt environnemental et social de ce processus récent.

La seconde partie s'intéresse aux finalités avancées par les décideurs afin d'entamer les processus de retour volontaire de la mer. L'auteure propose une classification autour de 6 finalités récurrentes : environnementale (afin d'accroitre la biodiversité, requalification paysagère), économique (moindre cout d'entretien ou de rehaussement des digues, développement du tourisme), compensatoire (soutien à l'économie locale, subventions régionales et européennes pour la reconversion agricole, le développement des structures touristiques), défensive (accroitre l'efficience des digues si elles sont protégées par une slikke). Les autres catégories relèvent de l'hybridation de ces quatre finalités majeures. Tout ceci renforce le débat actuel autour de la « renaturation » des espaces et le retour à certaines formes d'ensauvagement.

La troisième partie traite de l'articulation entre les dynamiques et les entraves à la dépoldérisation. L'auteur montre que le statut juridique des zones côtières concernées joue un rôle contribuant à rendre le retour volontaire de la mer plus aisé. Aux Pays-Bas, le statut public de la zone côtière facilite la dépoldérisation surtout si le polder a perdu son caractère agricole. En Grande-Bretagne, les propriétés en bordure du littoral couvrent aussi les estrans. En cas de reprofilage et de recul des digues, les propriétaires conservent les prés salés ainsi libérés et cela contribue à diminuer les oppositions à la dépoldérisation.
Le rapport des sociétés avec leur nature est aussi variable. Ainsi en Grande-Bretagne l'intérêt pour l'ornithologie depuis le début de l'industrialisation, conjugué à l'essor des sociétés de protection de la nature contribue à expliquer le ressentie favorable des populations. L'auteure aborde à nouveau la géographie des représentations en explorant le ressenti différencié des populations face à la dangerosité des tempêtes. La catastrophe consécutive à la tempête de février 1953 en Zélande a contribué à renforcer les craintes vis-à-vis du démantèlement des digues.

Se pose aussi la question de la bonne échelle géographique d'intervention. Il semblerait que les dépoldérisations les plus étendues aient aussi l'impact environnemental (filtrage des nitrates, frayères) le plus performant.

La dernière partie de l'ouvrage aborde la nécessaire prise en compte des participations locales aux processus de décision qui doivent accompagner les chantiers de dépoldérisation dans les perspectives de la GIZC. L'auteure s'appuie sur 6 terrains d'enquêtes réalisées en France et en Grande-Bretagne qui montrent les opinions vis-à-vis de différentes opérations par brèche accidentelle, démantèlement ou alignement. Une corrélation semble se dessiner entre une dépoldérisation planifiée nécessitant des travaux qui est assez bien acceptée (par exemple à Noirmoutier) et au contraire les cas ou on laisse faire la nature, une situation qui semble générer le plus de craintes de la part des riverains et utilisateurs.

Lydie Goeldner-Gianella poursuit en détaillant un exemple de GIZC en baie de Somme. L'apport des entretiens qualitatifs permet de comprendre finement les arguments des agriculteurs, des chasseurs, des professionnels du tourisme, des associations et ONG de protection de la nature. L'auteure montre l'importance de cette participation sociale indirecte par l'intermédiaire des associations et des ONG. Les processus de décision de l'action publique sont détaillés par l'analyse des différentes réunions de cette GIZC et montre que « la philosophie d'intégration des avis locaux véhiculées par la politique de GIZC constitue un bon moyen de mieux faire accepter des projets qui étaient au départ controversés ou sensibles ». Plus qu'une concertation, il s'agit d'une participation à l'action publique, même si la gouvernance reste exogène et peu pilotée par les acteurs locaux. 
La conclusion ouvre sur les processus de dépoldérisation à l'échelle mondiale qui restent dépendants de la pression agricole et du changement climatique et sont en perpétuelle évolution. Au total, Lydie Goeldner-Gianella signe ici un ouvrage de base pour tous ceux qui désirent comprendre en finesse et en profondeur l'évolution récente des sociétés littorales et leur regard sur un littoral anthropisé : les polders, dans un contexte de pressions réelles ou supposées liées aux prévisions de remontées du niveau des mers et des océans.

Michel Desse 